5 Valéry Legrain ${ }^{1,2, *}$, Flavia Mancini $^{3,4}$, Chiara F Sambo $^{5}$, Diana M Torta ${ }^{6}$, Irene Ronga ${ }^{5,7}$, \& Elia

6 Valentini ${ }^{8,9}$.

\section{Cognitive aspects of nociception and pain. Bridging neurophysiology with cognitive psychology.}

Aspects cognitifs de la nociception et de la douleur. Le rapprochement de la neurophysiologie et de la psychologie cognitive.

1 Department of Experimental Clinical and Health Psychology, Ghent University, Ghent, Belgium.

2 Institute of Neuroscience, Université catholique de Louvain, Louvain-la-Neuve \& Brussels, Belgium.

3 Institute of Cognitive Neuroscience, University College London, London, United Kingdom.

4 Department of Psychology, Università degli Studi di Milano-Bicocca, Milan, Italy.

5 Department of Neuroscience, Physiology \& Pharmacology, University College London, London, United Kingdom.

6 Department of Psychology, Università degli Studi di Torino, Turin, Italy.

7 Department of Neuroscience, Università degli Studi di Torino, Turin, Italy.

8 Department of Psychology, Sapienza - Università di Roma, Rome, Italy.

9 Fondazione Santa Lucia, Istituto di Ricovero e Cura a Carattere Scientifico, Rome, Italy.

* corresponding author: Department of Experimental Clinical and Health Psychology, Ghent University, Henri Dunantlaan 2, 9000 Ghent, Belgium Tel.: +32 926491 43. Fax: +329264 6489.

E-mail address: valery.legrain@ugent.be 


\section{Abstract}

The event-related brain potentials (ERPs) elicited by nociceptive stimuli are largely influenced by vigilance, emotions, alertness and attention. Studies that have specifically investigated the effects of cognition on the nociceptive ERPs support the idea that most of the components of these ERPs can be regarded as the neurophysiological indexes of the processes underlying the detection and the orientation of attention toward the eliciting stimulus. Such detection is determined by the salience of the stimulus that makes it pop out from the environmental context (bottom-up capture of attention) and by its relevance according to the subject's goals and motivation (top-down attentional control). The fact that nociceptive ERPs are largely influenced by information from other sensory modalities such as vision and proprioception, as well as from motor preparation, suggests that these ERPs reflect a cortical system involved in the detection of potentially meaningful stimuli for the body, with the purpose to respond adequately to potential threats. In such a theoretical framework, pain is seen as an epiphenomenon of warning processes, encoded in multimodal and multiframe representations of the body, well suited to guide defensive actions. The findings here reviewed highlight that the ERPs elicited by selective activation of nociceptors may reflect an attentional gain apt to bridge a coherent perception of salient sensory events with action selection processes.

Keywords: nociception, pain, event-related potentials, cognition, attention, executive functions, body, space, action 


\section{Résumé}

Les potentiels évoqués cérébraux (PE) induits par des stimuli nociceptifs sont largement influencés par la vigilance, les émotions, l'attention-alerte et l'attention sélective. Les études ayant spécifiquement exploré les effets de facteurs cognitifs sur les PE nociceptifs soutiennent l'idée selon laquelle la plupart des composantes de ces PE peuvent être considérées comme les indices neurophysiologiques des processus sous-jacents de la détection et l'orientation de l'attention vers le stimulus évoquant. Cette détection est déterminée par la saillance du stimulus qui le rend particulièrement émergeant par rapport au contexte environnemental (capture ascendante de l'attention) et par sa pertinence par rapport aux objectifs cognitifs et à la motivation du sujet (contrôle attentionnel descendant). Le fait que les PE nociceptifs soient largement influencés par les informations provenant d'autres modalités sensorielles comme la vision et la proprioception, ainsi que par la préparation motrice suggèrent que ces PE reflètent un système cortical impliqué dans la détection des stimuli potentiellement significatifs pour l'organisme dans le but de répondre adéquatement aux menaces éventuelles. Dans un tel cadre théorique, la douleur est considérée comme un épiphénomène des processus d'alerte, intégré dans des représentations multimodales et multi-référentielles du corps dont le but est de guider la réalisation des comportements de défense. Les données présentées dans cet article soulignent que les PE obtenus en réponses à des stimulations sélectives des nocicepteurs peuvent représenter l'activité des mécanismes de contrôle du gain attentionnel permettant de coordonner de façon cohérente la perception d'événements sensoriels saillants et la sélection de la réponse.

Mots clés: nociception, douleur, potentiels évoqués, cognition, attention, fonctions exécutives, corps, espace, action 


\section{Introduction}

Since the first recordings of computer-averaged event-related potentials (ERPs) and eventrelated magnetic fields (ERFs), these techniques were proposed as suitable methods to investigate human cognition (e.g. $[98,109])$, i.e. the cortical operations "by which the sensory input is transformed, reduced, elaborated, stored, recovered, and used" [77]. When for the first time Carmon et al. [12] obtained ERPs in response to selective activation of nociceptive A $\delta$ - and C-fiber by laser radiant thermal stimulation, they noticed that the nociceptive ERPs were less sensitive to variations of the physical parameters of the stimulation than to variations of the subject's perception. As a matter of fact, later studies showed that nociceptive ERPs are largely modified by vigilance $[3,6,83]$, emotional state $[19,21]$, alertness [69], and, even more, by the attention given to the stimulus [63]. The first generation of studies were mostly designed to investigate the influence of these factors in order to control them and to establish a reliable ERP recording protocol to be used in clinical settings [63]. Indeed, the primary interest was to use nociceptive-specific ERPs to assess dysfunctions of the nociceptive pathways [103]. Therefore, studies aimed to dissociate the so-called exogenous components of the nociceptive ERPs (supposed to reflect the selective and specific processing of the sensory inputs) from the endogenous ERP components (thought to reflect undesired psychological reactions of the patients). By contrast, the last decade of research tackled the issue of how nociceptive ERPs are modulated by cognitive factors, fostering the understanding of those processes underlying the detection, analysis, and reaction to the nociceptive event, i.e. the processes which underlie the interpretation of a nociceptive stimulus as a sensory event able to induce physical harm to the body. Data from this new course have been determinant in changing the understanding of the functional significance of cortical processes reflected by the nociceptive ERPs. 
The present article attempts to provide a synopsis of the literature relative to the cognitive modulations of the ERPs elicited by nociceptive and painful stimuli ${ }^{1}$. After a short review of the first generation of studies (paragraph 1; see [63]), a more in-depth discussion will deal with the role of cognitive factors underlying the detection and the reaction to sensory stimuli perceived as potential bodily threats.

\section{Directing vs. distracting attention}

It is largely admitted that paying attention to a nociceptive stimulus makes it more painful. On the contrary, focusing attention either on another perceptual object or on another task reduces pain (see [107]). The studies that have explored the influence of attention on the nociceptive ERPs were mostly inspired by the theoretical framework proposed by the limited-capacity models of human cognition (e.g. [9]) and adapted to pain research by, for example, Leventhal and Everhart [60], and McCaul and Malott [65]. These authors proposed that sensory inputs - including nociceptive ones may exceed processing capacity, and hence require attention to give priority to some inputs over others. Therefore directing the subject's attention away from the nociceptive stimuli would decrease the amount of attentional resources allocated to process the nociceptive inputs and thus reduce the resulting pain.

Based on these models, authors built paradigms in which nociceptive stimuli were intermixed with stimuli from another sensory modality and the participants were instructed either to attend the nociceptive stimuli by performing a task (e.g. counting them all $[38,67,75,82,83,106,110]$ or some of them [93], rating their intensity $[6,22]$, or even attending the stimuli without any specific instruction $[35,111,112])$, or to distract their attention from the nociceptive stimuli by performing a task on

\footnotetext{
${ }^{1}$ In the present paper, the term "nociceptive" is used to describe stimuli that selectively activate the nociceptive system, while the term "painful" is used to describe stimuli that elicit a perception of pain, regardless of the selectivity of the eliciting inputs.
} 
112

113

stimuli from another modality (e.g. arithmetic calculation of numbers $[6,22,82,83,106,111-113]$, reading a book [93], performing an oddball auditory task [38], a word puzzle [67] or a memory test [35]). Sometimes, in the distraction condition, participants were simply asked to ignore the nociceptive stimuli without any control procedure $[93,110]$. The most recurrent result of these studies (excepting [82]) was a reduction of the magnitude of the vertex positivity of the ERPs (i.e. P2) supposed to mainly reflect the activity of the anterior cingulate cortex (ACC) [37] when attention was directed to the pain-unrelated task, both in studies that used nociceptive-specific stimuli delivered by laser heat stimulator $[6,35,38,83,93,106,112,113]$ and studies that used unspecific electrocutaneous stimuli with an intensity rated as painful $[22,67,111]$. This $\mathrm{P} 2$ amplitude reduction was accompanied by a reduction of pain ratings, measured after each stimulation block $[35,38,82]$ or after the experiment [67], except in the study by Zaslansky et al. [113] who found no modulation of pain ratings. While the late $\mathrm{N} 2$ component was also often found to be modulated by attention $[6,38,112]$, results were less consistent regarding the early N1 component and its magnetoencephalographic counterpart (mN1) reflecting the earliest cortical processing in the somatosensory cortices [37, 104]. At a first glance, N1/mN1 was not found to be modulated by attention $[38,106,111,112]$. These results were interpreted as evidence that the early $\mathrm{N} 1$ reflected sensory processing impervious to cognitive modulation, whereas the late $\mathrm{P} 2$ reflected perceptual processing under the influence of attention. Therefore, it was proposed that the N1 was more suited for clinical examination than the P2. However, these conclusions were rapidly challenged by studies that found a clear modulation of the earliest ERP and ERF components with similar paradigms $[75,110]$ or with paradigms in which the spatial location of the stimuli on the body was manipulated $[5,54,91]$ (see $[8,45]$ for conflicting results). This strongly supports the fact that, as it was concluded by neuroimaging studies $[11,81,92]$, almost all cortical areas processing nociceptive inputs may have their activity modulated as a function of the attention directed to the stimulus [78], likewise reported in other sensory modalities $[40,74,84,88]$. 
Based on the results of the studies reviewed in this section, standard stimulation protocols were proposed to assess nociceptive processing by controlling the level of attention given to the stimuli [103]. However, the paradigms were built in such a way that it was difficult to disentangle the effects due to the intrinsic attentional modulation of nociceptive cortical responses from the effects due to overlapping unspecific brain activities. For instance, standard paradigms required the subjects to count or to rate the nociceptive/painful stimuli delivered at a slow rate. Nociceptive ERPs recorded in such conditions, especially the P2, could therefore be contaminated by unspecific ERP components such as the P300/P3b related to decision making $[4,39,43,44,48,54,55,79,93,102,113]$. Similarly, the slow rate of stimulation facilitated the generation of ERP components related to attentional orientation such as the P3a $[48,54]$.

\section{Bottom-up capture of attention.}

According to modern theories of attention, sensory inputs compete to be represented in the neural system $[20,46]$. Attention operates by biasing the processing and by selecting the most appropriate information for the ongoing behavioural and cognitive goals in order to guarantee coherent sensory-motor processing and to avoid the interference of irrelevant distracters. Such an attentional selection implies choices that have to be made to control voluntarily the information flow (top-down control). Nevertheless, attention can also be captured by sensory stimuli, independently of voluntary control, when they are salient enough to impose their own processing priority $[29,46]$. The salience of a stimulus refers to its physical distinctiveness and its ability to stand out relative to other sensory stimuli [29]. This property confers to a stimulus more ability to capture attention. Therefore, the bottom-up selection involves a shift of attention from its current focus to another one, so as to adapt behaviour to contextual constraints, such as the sudden occurrence of a potentially damaging stimulus [56]. 
161

162

163

164

165

166

167

168

169

170

171

172

173

174

175

176

177

178

179

180

181

182

183

184

185

The ability of painful stimuli to involuntarily capture attention was already observed in behavioural studies showing decrements of the performance in auditory discrimination tasks when the task was performed in the presence of task-irrelevant painful stimuli, resulting from a shift of attention from the auditory target towards the painful distracter (e.g. [15]). Noteworthy is that the ability of the stimuli to receive attention does not depend on their painfulness, and, more generally, on their sensory modality, but rather on the contextual relationship between co-occurring stimuli (i.e. their salience) and on the relative importance of each sensory event for the subject's goals (i.e. their relevance; see next section) [56].

Novelty is an important determinant to the salience of a stimulus: sensory events that are presented for the first time or infrequent events that differ from recent past events are highly distracting, i.e. they are more susceptible to capture attention from its focus and disrupt other ongoing cognitive activities [33]. To investigate the effect of novelty on nociceptive ERPs, Legrain et al. [57] presented their participants with series of visual stimuli, each of them preceded by a nociceptive laser stimulus. Participants were instructed to perform a task on the visual stimuli while the nociceptive stimuli were presented as irrelevant distracters. During most of the trials, nociceptive stimuli were delivered on a specific area of the hand (standard trials). Occasionally and unexpectedly, the position of the laser beam was shifted to another area of the hand. During these novel trials, the reaction times to the visual targets were slower compared to trials in which nociceptive stimuli were regularly presented on the same hand area. This suggests that nociceptive distracters captured the attention more when they were novel than when they were familiar. Interestingly, novel nociceptive stimuli elicited ERPs of larger amplitude than those elicited by standard nociceptive stimuli, despite the fact that stimuli from the two conditions had exactly the same energy. Similar ERP magnitude increases associated to stimulus novelty were observed when the location of the nociceptive stimuli was occasionally shifted from one hand to the other [48] or when their intensity was occasionally changed $[49,54,55]$, suggesting that modification of the ERP waveform was not conditioned by the 
186

187

physical dimension in which the change took place, but rather by the fact that the stimulus was detected as deviant.

In Dowman's experiments, painful electrical stimuli of different intensities were delivered on the right vs. left sural nerve, and, before each trial, the most likely spatial location of the forthcoming stimulus was cued $[23,25]$. In other experiments, somatosensory stimuli were intermixed with visual stimuli, and the most likely modality of the forthcoming stimulus was pre-cued [24]. Occasionally, in a small proportion of trials, the target stimulus was invalidly cued: it appeared at the wrong location, or belonged to the wrong modality. In these invalid infrequent conditions, stimuli elicited ERPs with greater amplitude, despite the fact that these stimuli were unattended. Dowman [25] interpreted these modifications of ERP amplitude as reflecting the activity of neural threat detectors, while other authors argued that such modifications are not dependent on the threat value and on the sensory modality of the eliciting stimulus $[56,57,73]$.

These studies showed that significant ERP modulations may take place when a change occurs occasionally, even unattended, in the stream of sensory events. Other experiments reported similar ERP modulations when the nociceptive stimulus is absolutely new (i.e. presented after a long break). Indeed, by administrating trains of three consecutive laser stimuli of identical intensity at a constant inter-stimulus time interval, the largest ERP amplitude was observed for the very first stimulus of the trains, while the magnitude of the ERPs evoked by the second and third stimuli was reduced, without any significant reduction of pain perception [42]. This magnitude modulation concerned all ERP components, including the early N1. In successive experiments, the same group tested the influence of changes introduced within the trains (bottom-up modulation), and controlled for the role of the participants' prior knowledge of these changes (top-down modulation) [101,105]. In these experiments, while the second stimulus was a repetition of the first one, the third stimulus could either belong to a different modality (e.g. a laser stimulus following two auditory stimuli) [105], or be delivered on a different body location [101]. While spatial change produced rather small effects, the 
211

212

213

214

introduction of a change of modality produced a dishabituation of ERPs, i.e. a significant increase of ERP magnitude for a mismatching third stimulus, as compared with ERPs elicited by the third stimuli preceded by identical stimuli. Such a dishabituation was observed regardless of top-down expectations.

Altogether, these data show that nociceptive laser stimuli and painful electrical stimuli elicit ERPs of larger amplitude when they are novel, i.e. when they are delivered for the first time and after a long break or when they represent a change relatively to the preceding sensory events. The fact that these modifications were observed even when nociceptive stimuli were completely irrelevant for the task and when attention was initially directed to another body location or to a stimulus of a different sensory modality $[49,54,57]$ suggests that stimulus novelty boosted cortical processing of nociceptive and painful stimuli irrespective of top-down factors such as the expectation of the occurrence of the change $[101,105]$. However, it does not mean that these modifications reflect mechanisms completely independent from voluntary control. Indeed, both task-relevant and -irrelevant novel stimuli evoke ERPs of large amplitude, but this effect is larger when the novel stimulus is the target of the task [54] (Fig. 1) and when the primary visual task requires a minimal level of attention resources to allow attentional shifting to the nociceptive distracters [49]. Therefore, ERP components such as the P2 would reflect the actual engagement of attention to the stimulus, instead of a pure automatic detection of novelty [57]. As the effect of novelty on N1 and N2 amplitude was less recurrently observed $[49,57,105]$, further studies are mandatory to elucidate the effect of the bottom-up capture of attention on early-latency nociceptive ERPs.

Interestingly, the modulation of the P2 amplitude induced by novel nociceptive stimuli is highly similar to the modulation observed for ERPs evoked by auditory, visual and tactile stimuli (i.e. P3a) [33]. These data further support the notion of a multimodal salience detection system that involves, among others, brain structures such as the insular and cingulate cortices $[26,27]$. This multimodal 
nature of the nociceptive ERPs cannot be interpreted as direct index of the subjective experience of pain $[56,73]$.

\section{Top-down control of attention and executive functions.}

As pain can be modified by attention [107], the manipulation of attention represents a potentially efficient therapeutic strategy in the clinical management of pain (e.g. [70]). On the other hand, it is also hypothesized that attention is involved in the persistence of pain symptoms [18]. However, clinical psychologists might wonder how to help patients to voluntarily control their attention to pain as painful stimuli are highly susceptible to capture attention involuntarily. As mentioned in the previous section, attention modifies sensory processing for the purpose of achieving ongoing cognitive goals or satisfying high-order motivational drives, defining the relevance of the stimulus, and inhibits interference from distracters. Recently, three factors were proposed as guarantors of an efficient attentional control over pain stimuli $[53,58]$. First, attention should be engaged in the processing of stimuli that are largely unrelated to pain and, more broadly, to somatosensation. This hypothesis originates from the notion of attentional set that defines a mental set of information corresponding to the stimulus features the subject needs to identify in order to perform a task [34]. Thus, the more segregated is the competing sensory information with respect to the ongoing pain the better will be the control over pain. Second, the engagement of attention should be effortful [1]. The more attentional resources are loaded on the achievement of a particular cognitive activity, the less they are available to process the distracters (attentional load) [47]. Finally, the engagement of attention toward pain-unrelated information should be controlled by executive functions that guarantee the full achievement of cognitive goals [66] and inhibit the intrusion of distracters [68]. 
One important consequence of the concept of attentional set is that stimuli which share common features with the relevant target, even if task-irrelevant, will capture attention more easily. This could explain why people who are hyper-responsive to body-related information are more easily distracted by somatosensory stimuli $[16,17]$. In an ERP experiment, during laser stimulation randomly delivered on the two hands, participants were instructed to identify target stimuli delivered on a specific hand. All the stimuli delivered on the relevant hand elicited ERPs of larger amplitude, regardless of whether they were targets or non-targets of the task, as compared to the ERPs elicited by similar stimuli delivered when the opposite hand was relevant [54] (Fig. 2). It was thereby proposed that nociceptive processing was biased by cognitive goals having set, in the present case, the spatial location of the stimuli as a relevant feature for the task. Since the amplitude modulation also affected the N1 component, these biases could affect the very early stage of cortical processing, as shown in other sensory modalities $[40,84]$. More interestingly, it was shown that the novelty effect on the P2 (i.e. the magnitude increase observed in response to occasional stimulus change) was larger for novel stimuli delivered to the attended hand (i.e. the target of the tasks) than for novel irrelevant stimuli with similar physical properties but delivered to the unattended hand (Fig. 1). This finding supports the idea that the bottom-up effect induced by stimulus novelty was under the control of the attentional set.

The role of attentional load was investigated in an ERP experiment in which nociceptive stimuli of the same intensity were delivered either in regular and homogenous series or as novel stimuli in series containing regular stimuli of lower intensity [49]. When the participants were instructed to perform a low-demanding visual task, novel nociceptive stimuli elicited ERPs (N2 and P2) of larger amplitude. In addition, reaction times to visual targets were slower if the nociceptive stimulation series contained the novel stimuli. But when the visual task required a higher load of attentional resources, the novelty effect on P2 magnitude (i.e. the difference between P2 evoked by novel stimuli and P2 evoked by regular stimuli) was reduced. These results were complemented by 
283

284

neuroimaging studies showing a significant reduction of metabolic activity in response to painful stimuli when the participants performed high-demanding pain-unrelated tasks $[2,7,92]$. However, it is important to note that increasing the attentional load on the visual task was not sufficient to reduce the disruptive effect: reaction times remained slower during the stimulation series with novel nociceptive stimuli, and participants made more errors [49]. This suggests that an experimental design which establishes an attentional set unrelated to pain (or to bodily information) does not fully prevent involuntary attentional shift as well as distraction from salient irrelevant stimuli to take place.

Therefore, it was proposed that an efficient attentional control over nociception and pain should also involve executive functions. For instance, working memory might help guiding attention to goalrelevant information [94], by maintaining active the attentional set during the achievement of cognitive goals, and by shielding goal-relevant information from interference. The role of working memory in the attentional control of nociception was recently tested [51-53]. Participants were asked to perform a task on visual stimuli, each of them being shortly preceded by a somatosensory distracter. Distracters were non-painful median-nerve electrical stimuli occasionally replaced by nociceptive laser stimuli. Because of the novelty of the nociceptive distracter, reaction times were longer in response to visual targets preceded by a nociceptive distracter than in response to similar targets preceded by a standard tactile distracter. However, when participants were asked to rehearse in working memory some features of the visual targets from trial to trial, the disruption was reduced: there was no difference between visual targets coupled with novel distracters and visual targets with standard somatosensory distracters [53], regardless of the attentional overload generated by the task [51]. In addition, the magnitude of the N1 and N2 ERPs was reduced during the working memory condition, suggesting a control by working memory over early cortical processing of nociceptive inputs [52]. Surprisingly, the P2 magnitude was reduced only during a working memory task consisting in delaying the response to a target to the next trial. Because this task is thought to 
manipulate the representation of the response associated to the target stimulus, it was therefore hypothesized that the modulation of the nociceptive-evoked P2 would reflect attentional processing associated with the selection of the motor response (see paragraph 5). Conversely, P2 amplitude was not affected by the instruction to rehearse in working memory the sensory features of the visual target.

\section{Multimodal interaction and spatial representations of the body.}

The studies described above provide converging evidence that the cortical processing of a nociceptive stimulus, as sampled with classic neurophysiological and neuroimaging techniques ${ }^{2}$, is strongly determined by the salience and the relevance of the stimulus. Therefore, it was proposed that ERPs elicited by nociceptive stimuli mainly reflect cortical processes involved in the orientation of attention when the stimulus is sufficiently distinctive to receive priority processing over other sensory inputs [56]. This hypothesis has received strong support from studies demonstrating that ERPs elicited by nociceptive and painful stimuli are not specifically related to the perception of pain [42] but represent a pattern of cortical activities that can also be generated by stimuli from other sensory modalities [73]. Therefore, the nociceptive ERPs could reflect the activities of a cortical network involved in an important but non-specific function of pain: that of detecting salient sensory events and prompting the appropriate response. Because salient stimuli can represent events with significant impact on the organism in terms of adaptation, it was proposed that this network could be particularly important to process significant sensory stimuli for the physical integrity of the body [56]. In other words, nociceptive ERPs would reflect the activity of a cortical system that could be used as

\footnotetext{
${ }^{2}$ It is important to emphasise that the claim according to which the cortical activity elicited by a nociceptive stimuli does not reflect the perception of pain $[42,56,73]$ is not meant to dismiss the existence of any cortical activity specifically involved in the generation of pain. Nevertheless, there is converging evidence that such an activity is not accessible to classic methodologies used to record and analyse brain activity [56]. This evidence calls for developing novel methods to characterise the cortical activity elicited by a nociceptive stimulus and its relationship to the perception of pain $[14,114]$.
} 
a defensive mechanism to detect, localize, and react to physical threat, whatever the modality of the threatening stimulus.

An efficient localization of external sensory events involves the ability of the brain to represent space according to different frames of reference [13]. In addition, it is known that the brain can construct coherent spatial representations of the body and of the surrounding space by integrating information from different sources, i.e. somatosensory, proprioceptive, vestibular, visual [95]. The role of multimodal representations of the body and the peripersonal space is well documented by studies investigating tactile processing, including ERP studies [88]. Indeed, it has been consistently shown that viewing the stimulated body part or visual cues close to the stimulated body part enhances the magnitude of the ERPs induced by tactile stimulation of that body part $[30,31,89,99]$, and that such a modulation is also influenced by body posture [32]. These studies have shown that the influence of vision on tactile processing depends on the close spatial proximity between the visual stimulus and the tactile stimulation of the body [87].

Although multimodal integration of nociception with stimuli from the other sensory modalities has received less attention, there is some evidence that nociceptive processing is largely modulated by vision and proprioception. This claim is supported by clinical neuropsychological studies. For instance, Hoogenraad et al. [41] reported a case of a neglect patient with a right parietal lesion who suffered from hemianesthesia for both nociception and touch, which manifested specifically when the stimulus was applied while the patient had his eyes closed. In contrast, when the patient had his eyes open and saw the sensory testing tool approaching his contralesional limb, he reported a sensation of burning pain in the arm. In addition, it was shown that patients suffering from complex regional pain syndrome (CRPS) tend to neglect their affected limb [50]. More importantly, their neglect-like symptoms are influenced by the vision of the limbs [72] and by the posture [71], thus suggesting that neglect symptoms of CRPS do not depend on a purely somatotopic representation of pain $[50,71]$. Intriguingly, when CRPS patients were asked to indicate in the dark what they estimated 
354

355

356

357

358

359

360

361

362

363

364

365

366

367

to be the midline of their body, they neglected the opposite side of space, i.e. the side corresponding to the location of the healthy limb $[96,97]$. When the visual field of the patients was shifted by prismatic glasses toward the hemispace corresponding to the unaffected limb, CRPS symptoms, including neglect-like symptoms and pain, were alleviated $[10,96]$. In healthy participants, an ERP study showed a significant influence of viewing the stimulated hand on the magnitude of laserevoked potentials [61]. Participants were looking directly at their stimulated hand or an image of that hand manipulated through a mirror illusion (see [85]). In this latter condition, the stimulated hand was placed behind a mirror aligned with the participant's sagittal plane and the illusion of seeing that hand was created while the participant was actually seeing the mirror-reflected image of the opposite hand. This illusion was created in order to disambiguate whether the effect was driven by viewing one's own hand or the threatening stimulus on the hand (i.e. the laser beam). As compared to control conditions in which the stimulated hand was out of sight and masked by a neutral object, or the participants were looking at the experimenter's hand, laser stimuli were rated as less intense and evoked ERPs of smaller amplitude when the participants looked at their own stimulated hand. Similarly, Mancini et al. [64] showed that viewing one's own hand increases pain threshold, in comparison to viewing an object in the same location. They demonstrated that the visual appearance of the hand further modulates pain perception. The participants' hand was observed through a distorting mirror so that the size of the visual image appeared magnified or minified. Enlarging the visual image of the hand enhanced the reduction of pain, while reducing the visual image of the hand decreased the reduction of pain. The results from the two latter studies $[61,64]$ are surprising as, based on the known mechanisms of spatial attention, one should expect that looking at the hand would direct spatial attention in a cross-modal way to that location [30], which would amplify nociceptive processing [54], and therefore increase pain [108]. In contrast, it was proposed that the reduction of pain by viewing the body could be mediated by an integration of the body part in pain within a stable representation of the body [62]. Noteworthy is that the reverse pattern was observed in CRPS patients [72], perhaps due to specific aspects of CRPS pathophysiology. 
Regarding the influence of proprioception, Gallace et al. [36] showed a modulatory effect of hand posture on nociceptive ERPs. Non-nociceptive electrocutaneous and nociceptive laser stimuli were applied distinctly on one of the hands, while the vision of the hands was precluded by a screen. Participants were tested with the hands in a canonical posture vs. in a crossed posture (relatively to the sagittal midline of the trunk). Both the perceived intensity and the magnitude of the evoked ERPs (N2/P2, but not N1) were reduced for stimuli applied during the crossed posture relative to the canonical posture. Finally, a recent study provided compelling evidence that body posture modulates not only the cortical processing but also the subcortical activity elicited by electrocutaneous stimulation. Sambo et al. [90] showed that the proximity of the hand to the face, which was manipulated both by changing the position of the hand and by rotating the head, modulated the excitability of the brainstem circuits mediating the blink reflex elicited by intense electrical stimulation of the median nerve at the wrist. That is, when the hand entered the proximal space surrounding the face, the electromyographic correlate of the blink reflex elicited by the stimulation of the hand showed an earlier onset, longer duration, and greater amplitude (Fig. 3). This suggests that multimodal areas responsible for remapping the location of somatosensory stimuli according to the current body posture exert a tonic modulation of the brainstem circuits of the hand-elicited blink reflex.

\section{From sensory processing to action}

The P2 wave elicited by nociceptive stimuli is reduced when the participants have to keep in working memory the representation of the response associated to a concurrent visual target, but not when it involves the rehearsal of the sensory features of that visual target [52]. Other authors

402 showed that the delivery of laser stimuli during the preparation of a motor response to a visual 403 stimulus elicited ERPs of weaker amplitude if the laser stimuli were ipsilateral to the prepared hand movement [59]. These findings may hint to interpret the P2 wave as reflecting processes related to 
405

the selection of motor responses. This hypothesis finds supporting evidence in the identification of the mid-section of the cingulate cortex as the main generator of P2 [37], an area involved in motor processing $[28,100]$. Primary motor and supplementary motor areas were also proposed as potential generators of the nociceptive ERPs [80]. Therefore, one might hypothesize that the P2 generators (or at least part of them) could reflect the selection and the preparation of the appropriate action in response to the most salient stimulus in the environment. However, to date, most of the electrophysiological studies that directly investigated the relationship between nociception and motor function tested the effect of movements on the nociceptive ERPs with the aim to understand the neurophysiological mechanisms underlying the analgesic effect of motor cortex stimulation (e.g. [76]). Thus, further investigation on the role of the P2 vertex positivity as an index of cortical processes related to action preparation and selection is needed.

\section{Conclusion}

The studies reviewed here support the idea that classic ERPs elicited by nociceptive stimuli represent the cortical activity related to an important but non-specific function of pain: to detect and react against stimuli that are potentially significant for the physical integrity of the body. In such a theoretical framework, these cortical responses could represent the joined activity of three major processes. The first process detects and orients attention selectively to the most salient sensory event in order to prioritize its processing. The salience of a stimulus is defined by its physical properties making it contextually conspicuous with respect to other surrounding stimuli. But it can be modulated by the relevance of the stimuli in relation to the subject's cognitive goals, on the effort exerted to achieve these goals and on the executive control over interference between competing sensory inputs. The second process is involved in the spatial localization of the stimulus using spatial frames of reference that integrate the stimulus in global and multimodal representations of the body and the proximal space. The third process reflects cognitive operations apt to bridge a coherent 
430

431

433

434

435

436

437

438

439

440

441

442

443

444

445

446

447

448

449

450

451

452

perception of salient sensory events with action selection in order to prepare and triggers the most appropriate motor response to the stimulus.

Such perspective provides support to, and is in turn supported by, clinical application. Indeed, the therapeutic potential to alleviate pain experience in chronic pain patients $[10,96]$, as shown by the mirror box [85] and the prism adaptation technique [86], is largely grounded on the notion of a multimodal representation of the body. These clinical studies, in addition to the ERP studies reviewed here, support the idea of a close interplay between the processing of sensory inputs arising from multiple sources and cognitive functions ranging from attentional capture to action selection. This highlights the potential synergy between medical intervention and neuropsyhological rehabilitation for the treatment of pain and other sensory-motor deficits associated with chronic pain diseases (see [50]).

\section{Acknowledgements}

Valéry Legrain is supported by the Research Foundation Flanders (FWO), Belgium.

\section{References}

[1] Allport A. Selection for action: Some behavioral and neurophysiological considerations of attention and action. In: Heuer $\mathrm{H}$, Sanders AF, eds. Perspectives on perception and action. Hillsdale: Erlbaum; 1987. p. 395-419.

[2] Bantick SJ, Wise RG, Ploghaus A, Clare S, Smith SM, Tracey I. Imaging how attention modulates pain in humans using functional MRI. Brain 2002; 125: 310-319.

[3] Bastuji H, Perchet C, Legrain V, Montes C, Garcia-Larrea L. Laser evoked responses to painful stimulation persist during sleep and predict subsequent arousal. PAIN 2008; 137: 589-99. 
453 [4] Becker DE, Haley DW, Urena VM, Yingling CD. Pain measurement with evoked potentials: combination of subjective ratings, randomized intensities, and long interstimulus intervals produces a P300-like confound. PAIN 2000; 84: 37-47.

[5] Bentley DE, Watson A, Treede RD, Barrett G, Youell PD, Bulkarni B, Jones AKP. Differential effects on the laser evoked potential of selectively attending to pain localization versus pain unpleasantness. Clin Neurophysiol 2004; 15: 1846-6.

[6] Beydoun A, Morrow TJ, Shen JF, Casey KL. Variability of laser-evoked potentials: attention, arousal and lateralized differences. Electroencephalogr clin Neurophysiol 1993; 88: 173-81.

[7] Bingel U, Rose M, Gläscher J, Büchel C. fMRI reveals how pain modulates visual object processing in the ventral visual stream. Neuron 2007; 55: 157-167.

[8] Boyle Y, ElDereby W, Martinez Montes E, Bentley DE, Jones AKP. Selective modulation of nociceptive processing due to noise distraction. PAIN 2008; 138: 630-40.

[9] Broadbent DE. Perception and communication. London: Pergamon; 1958.

[10]Bultitude JH, Rafal RD. Derangement of body representation in complex regional pain syndrome: report of a case treated with mirror and prisms. Exp Brain Res 2010; 204: 409-18.

[11]Bushnell MC, Duncan GH, Hofbauer RK, Ha B, Chen Jl, Carrier B. Pain perception: is there a role for primary somatosensory cortex? Proc Natl Acad Sci USA 1999; 96: 7705-9.

[12]Carmon A, Mor J, Goldberg J. Evoked cerebral responses to noxious thermal stimuli in humans. Exp Brain Res 1976; 25: 103-7.

[13]Colby CL, Goldberg ME. Space and attention in parietal cortex. Annu Rev Neurosci 1999; 22: 31949.

[14]Colon E, Legrain V, Mouraux A. Steady-state evoked potentials to study the processing of tactile and nociceptive somatosensory input in the human brain. Neurophysiol Clin 2012, in press. influence of predictability on pain. Behav Res Ther1994; 32: 611-22. 
478

479

480

481

482

483

484

485

486

487

488

489

490

491

492

493

494

495

496

497

498

499

500

501

502

[16]Crombez G, Eccleston C, Baeyens F, Eelen P. Attentional disruption isenhanced by the threat of pain. Behav Res Ther 1998; 36: 195-204.

[17]Crombez G, Eccleston C, Bayens F, Eelen P. When somatic informationthreatens, catastrophic thinking enhances attention interference. Pain 1998; 75: 187-198.

[18]Crombez G, Van Damme S, Eccleston C. Hypervigilance to pain: an experimental and clinical analysis. PAIN 2005; 116: 4-7.

[19]De Pascalis V, Magurano MR, Bellusci A. Pain preception, somatosensory event-related potentials and skin conductance responses to painful stimuli in high, mid, and low hypnotizable subjects: effects of differential pain reduction strategies. PAIN 1999; 83: 499-508.

[20]Desimone R, Duncan J. Neural mechanisms of selective visual attention. Annu Rev Neurosci 1995; 18: $193-222$.

[21]Dillmann J, Miltner WHR, Weiss T. The influence of semantic priming on event-related potentials to painful laser-heat stimuli in humans. Neurosci Lett 2000; 284: 53-56.

[22]Dowman R. Distraction produces an increase in pain-evoked anterior cingulate activity. Psychophysiology 2004; 41: 613-24.

[23]Dowman R. Electrophysiological indices of orienting attention toward pain. Psychophysiology 2004; 41: 749-61.

[24]Dowman R. Neural mechanisms of detecting and orienting attention toward unattended threatening somatosensory targets. I. Intermodal effects. Psychophysiology 2007; 44: 407-419.

[25]Dowman R. The role of somatic threat feature detectors in the attentional bias toward pain: effects of spatial attention. Psychophysiology 2011; 48: 397-409.

[26]Downar J, Crawley AP, Mikulis DJ, Davis KD. A multimodal cortical network for the detection of changes in the sensory environment. Nature Neurosci 2000; 3:277-283.

[27]Downar J, Mikulis DJ, Davis KD. Neural correlates of the prolonged salience of painful stimulation. Neurolmage 2003; 20:1540-1551. 
503

[28]Dum RP, Levinthal DJ, Strick PL. The spinothalamic system targets motor and sensory areas in the cerebral cortex of monkeys. J Neurosci 2009; 29: 14223-35.

[29]Egeth HE, Yantis S. Visual attention: control, representation, and time course. Annu Rev Psychol 1997; 48: 269-97.

[30]Eimer M, Driver J. An event-related brain potential study of cross-modal links in spatial attention between vision and touch. Psychophysiology 2000; 37: 697-705.

[31]Eimer M, Forster B, Fieger A, Harbich S. Effects of hand posture on preparatory control processes and sensory modulations in tactile-spatial attention. Clin Neurophysiol 2004; 115: 596-608.

[32]Eimer M, Forster B, Van Velzen J. Anterior and posterior attentional control systems use different spatial reference frames: ERP evidence from covert tactile-spatial orienting. Psychophysiology 2003; 40: 924-33.

[33]Escera C, Corral MJ. Role of mismatch negativity and novelty-P3 in involuntary auditory attention. J Psychophysiol 2007; 21: 251-64.

[34]Folk CL, Remington RW, Johnston JC (1992) Involuntary covert orienting iscontingent on attentional control settings. J Exp Psychol Hum Percept Perform 1992; 18: 1030-1044.

[35]Friederich M, Trippe RH, Özcan M, Weiss T, Hecht H, Miltner WHR. Laser-evoked potentials to noxious stimulation during hypnotic analgesia and distraction of attention suggest different brain mechanisms of pain control. Psychophysiology 2001; 38: 768-76.

[36]Gallace A, Torta DM, Moseley GL, lannetti GD. The analgesic effect of crossing the arms. PAIN 2011; 152: 1418-23.

[37]Garcia-Larrea L, Frot M, Valeriani M. Brain generators of laser-evoked potentials: from dipoles to functional significance. Neurophysiol Clin 2003; 33: 279-92.

[38]Garcia-Larrea L, Peyron R, Laurent B, Mauguière F. Association and dissociation between laserevoked potentials and pain perception. NeuroReport 1997; 8: 3785-9.

[39]Hatem SM, Plaghki L, Mouraux A.How response inhibition modulates nociceptive and nonnociceptive somatosensory brain-evoked potentials. Clin Neurophysiol 2007; 118: 1503-16. 
529 [40]Hillyard SA, Vogel EK, Luck SJ. Sensory gain control (amplification) as a mechanism of selective attention: electrophysiological and neuroimaging evidence. Phil Trans R Soc Lond B 1998; 353, 1257-70.

532 [41]Hoogenraad TU, Ramos LM, van Gijn J. Visually induced central pain and arm withdrawal after right parietal lobe infarction. J Neurol Neurosurg Psychiatr 1994; 57: 850-2.

534 [42]lannetti GD, Hughes NP, Lee MC, Mouraux A. Determinants of laser-evoked EEG responses: pain perception or stimulus saliency? J Neurophysiol 2008; 100: 815-28.

[43]Kanda M, Fujiwara N, Xu X, Shindo K, Nagamine T, Ikeda A, Shibasaki H. Pain-related and cognitive components of somatosensory evoked potentials following $\mathrm{CO} 2$ laser stimulation in man. Electroencephalogr clin Neurophysiol 1996; 100: 105-14.

[44]Kanda M, Matsuhashi M, Sawamoto N, Oga T, Mima T, Nagamine T, Shibasaki H. Cortical potentials related to assessment of pain intensity with visual analogue scale (VAS). Clin Neurophysiol 2002; 113: 1013-24.

[45]Kanda M, Shindo K, Xu X, Fujiwara N, Ikeda A, Nagamine T, Shibasaki H. Cortical mechanisms underlying point localization of pain spot as studied by event-related potentials following $\mathrm{CO} 2$ laser stimulation in man. Exp Brain Res 1999; 127: 131-40.

[46]Knudsen El. Fundamental components of attention. Annu Rev Neurosci 2007; 30: 57-78.

[47]Lavie N. Distracted and confused?: selective attention under load. Trends Cogn Sci 2005; 9: 7582.

[48]Legrain V, Bruyer R, Guérit JM, Plaghki L. Nociceptive processing in the human brain of infrequent task-relevant and task-irrelevant noxious stimuli. A study with ERPs elicited by $\mathrm{CO} 2$ laser radiant heat stimuli. PAIN 2003; 103: 237-48.

[49]Legrain V, Bruyer R, Guérit JM, Plaghki L. Involuntary orientation of attention to unattended deviant nociceptive stimuli is modulated by concomitant visual task difficulty. Evidence from laser evoked potentials. Clin Neurophysiol 2005 116: 2165-74. 
554 [50]Legrain V, Bultitude JH, De Paepe AL, Rossetti Y. Pain, body, and space. What do patients with complex regional pain syndrome really neglect? PAIN 2012; 153: 948-51.

556 [51]Legrain V, Crombez G, Mouraux A. Controlling attention to nociceptive stimuli with working memory. PLoS ONE 2011; 6: e20926.

558 [52]Legrain V, Crombez G, Plaghki, L, Mouraux A. Shielding cognition from nociception with working 559 memory. In revision.

560 [53]Legrain V, Crombez G, Verhoeven K, Mouraux A. The role of working memory in the attentional control of pain. PAIN 2011, 152: 453-9.

562

[54]Legrain V, Guérit JM, Bruyer R, Plaghki L. Attentional modulation of the nociceptive processing into the human brain: selective spatial attention, probability of stimulus occurrence, and target detection effects on laser evoked potentials. PAIN 2002; 99: 21-39.

[55]Legrain V, Guérit JM, Bruyer R, Plaghki L. Electrophysiological correlates of attentional orientation in humans to strong intensity deviant nociceptive stimuli, inside and outside the focus of spatial attention. Neurosci Lett 2003; 339: 107-10.

[56]Legrain V, lannetti GD, Plaghki L, Mouraux A. The Pain Matrix reloaded. A salience-detection system for the body. Prog Neurobiol 2011; 93: 111-24.

[57]Legrain V, Perchet C, Garcia-Larrea L. Involuntary orienting of attention to nociceptive events. Neural and behavioral signatures. J Neurophysiol 2009; 102: 2423-34.

[58]Legrain V, Van Damme S, Eccleston C, Davis, KD, Seminowicz DA, Crombez G. A neuro-cognitive model of attentional control over pain. Behavioral and neuroscience evidence. PAIN 2009; 144: $230-2$.

[59]Le Pera D, Brancucci A, De Armas L, Del Percio C, Miliucci R, Babiloni C, et al. Inhibitory effect of voluntary movement preparation on cutaneous hat pain and laser-evoked potentials. Eur J Neurosci 2007; 25: 1900-7.

[60]Leventhal H, Everhart D. Emotions, pain, and physical illness. In: Izard CE, Ed. Emotions in Personnality and Psychopathology. New York: Plenum Press; 1979, p. 263-299.; 
580 [61]Longo MR, Betti V, Aglioti SM, Haggard P. Visually induced analgesia: seeing the body reduces $581 \quad$ pain. J Neurosci 2009; 29: 12125-30.

582 [62]Longo MR, lannetti GD, Mancini F, Driver J, Haggard P. Linking pain and the body: neural $583 \quad$ correlates of visually induced analgesia. J Neurosci 2012; 32: 2601-07.

584 [63]Lorenz J, Garcia-Larrea L. Contribution of attentional and cognitive factors to laser evoked brain 585 potentials. Neurophysiol Clin 2003; 33: 293-301.

586 [64]Mancini F, Longo MR, Kammers MP, Haggard P. Visual distortion of body size modulates pain 587 perception. Psychol Sci 2011; 22: 325-30.

588

[65]McCaul KD, Malott JM. Distraction and coping with pain. Psychol Bull 1984; 95: 516-33.

589

[66]Miller EK, Cohen JD. An integrative theory of prefrontal cortex function. Annu Rev Neurosci 2001;

590 24: 167-202.

591

[67]Miltner W, Johnson R Jr, Braun C, Larbig W. Somatosensory event-related potentials to painful and non-painful stimuli: effects of attention. PAIN 1989; 38: 303-12.

[68]Miyake A, Friedman NP, Emerson MJ, Witzki AH, Howerter A. The unity and diversity of executive functions and their contributions to complex "frontal lobe" tasks: a latent variable analysis. Cogn Psychol 2000; 40: 49-100.

[69]Miyazaki M, Shibasaki H, Kanda M, Xu X, Shindo K, Honda M, Ikeda A, Nagamine T, Kaji R, Kimura hand: scalp topography and effect of predictive warning signal. J clin Neurophysiol 1994; 11: 24254.

[70]Morley S, Shapiro DA, Biggs J. Developing a treatment manual for attention management in 601 chronic pain. Cogn Behav Ther 2004; 32:1-12.

602

[71]Moseley GL, Gallace A, Spence C. Space-based, but not arm-based, shift in tactile processing in 603 complex regional pain syndrome and its relationship to cooling of the affecting limb. Brain 2009; 132: 3142-51. 
605

606

607

608

609

610

611

612

613

614

615

616

617

618

619

620

621

622

623

624

625

626

627

628

629

[72]Moseley GL, Parsons TJ, Spence C. Visual distortion of a limb modulates the pain and swelling evoked by movement. Curr Biol 2008; 18: R1047-8.

[73]Mouraux A, lannetti GD. Nociceptive laser-evoked brain potentials do not reflect nociceptivespecific neural activity. J Neurophysiol 2009; 101: 3258-69.

[74]Näätänen R, Picton T. The N1 wave of the human electric and magnetic response to sound: a review and an analysis of the component structure. Psychophysiology 1987; 24: 375-425.

[75]Nakamura Y, Paur R, Zimmermann R, Bromm B. Attentional modulation of human pain processing in the secondary somatosensory cortex: a magnetoencephalographic study. Neurosci Lett 2002; 328: 29-32.

[76]Nakata H, Sakamoto K, Honda Y, Mochizuki H, Hoshiyama M, Kakigi R. Centrifugal modulation of human LEP components to a task-relevant noxious stimulation triggering voluntary movement. Neurolmage 2009; 45: 129-42.

[77]Neisser U. Cognitive psychology. New York: Meredith; 1967.

[78]Ohara S, Crone NE, Weiss N, Vogel H, Treede RD, Lenz FA. Attention to pain is processed at multiple cortical sites in man. Exp Brain Res 2004; 156: 513-7.

[79]Opsommer E, Guérit JM, Plaghki L. Exogenous and endogenous components of ultralate (C-fibre) evoked potentials following $\mathrm{CO} 2$ laser stimuli to tiny skin surface areas in healthy subjects. Neurophysiol Clin2003; 33:78-85.

[80]Perchet C, Godinho F, Mazza S, Frot M, Legrain V, Magnin M, Garcia-Larrea L. Evoked potentials to nociceptive stimuli delivered by CO2 or Nd:YAP laser. Clin Neurophysiol 2008; 119: 2615-22.

[81]Petrovic P, Petersson KM, Ghatan PH, Stone-Elander S, Ingvar M. Pain-related cerebral activation is altered by a distracting cognitive task. PAIN 2000; 85 : 19-30.

[82]Plaghki L, Delisle D, Godfraind JM. Heterotopic nociceptive conditioning stimuli and mental task modulate differently the perception and physiological correlates of short $\mathrm{CO} 2$ laser stimuli. PAIN 1994; 57: 181-92. 
630 [83]Qiu Y, Inui K, Wang X, Tran TD, Kakigi R. Effects of attention, distraction and sleep on CO2 laser 631 evoked potentials related to C-fibers in humans. Clin Neurophysiol 2002; 113: 1579-85.

632 [84]Rauss K, Schwartz S, Pourtois G. Top-down effects on early visual processing in humans: a 633 predictive coding framework. Neurosci Biobehav Rev 2011; 35: 1237-53.

634 [85]Ramachandran VS, Rogers-Ramachandran D, Cobb S.Touching the phantom limb. Nature 1995; $635 \quad 377: 489-90$.

636 [86]Rossetti Y, Rode G, Pisella L, Farnè A, Li L, Boisson D, Perenin MT. Prism adaptation to a rightward optical deviation rehabilitates left hemispatial neglect. Nature 1998; 395: 166-9.

638

[87]Sambo CF, Forster B. An ERP investigation on visuotactile interactions in peripersonal and extrapersonal space: evidence for the spatial rule. J Cogn Neurosci 2009; 21: 1550-9.

640

[88]Sambo CF, Forster B. Sustained spatial attention in touch modality-specific and multimodal mechanisms. ScientificWorldJournal 2011; 11: 199-213.

[89]Sambo CF, Gillmeister H, Forster B. Viewing the body modulates neural mechanisms underlying sustained spatial attention in touch. Eur J Neurosci 2009; 30: 143-50.

[90]Sambo CF, Liang M, Cruccu G, lannetti GD. Defensive peripersonal space: The blink reflex evoked by hand stimulation is increased when the hand enters the peripersonal space surrounding the face. J Neurophysiol 2012; 107: 880-9.

[91]Schlereth T, Baumgärtner U, Magerl W, Stoeter P, Treede RD. Left-hemisphere dominance in early nociceptive processing in the human parasylvian cortex. Neuroimage 2003; 20:441-54.

[92]Seminowicz DA, Mikulis DJ, Davis KD. Cognitive modulation of pain-related brain responses 650 depends on behavioral strategy. PAIN 2004; 112: 48-58.

651

[93]Siedenberg R, Treede RD. Laser-evoked potentials: exogenous and endogenous components. ElectroencephalogrclinNeurophysiol 1996; 100: 240-9.

653

[94]Soto D, Hodsoll J, Rotshtein P, Humphreys GW. Automatic guidance of attention from working memory. Trends Cogn Sci 2008; 12: 342-8. 
655 [95]Spence C, Driver J, eds. Crossmodal space and crossmodal attention. Oxford: Oxford University $656 \quad$ Press; 2004.

657 [96]Sumitani M, Rossetti Y, Shibata M, Matsuda Y, Sakaue G, Inoue T, Mashimo T, Miyauchi S. Prism 658 adaptation to optical deviation alleviates pathologic pain. Neurology 2007; 68: 128-33

659 [97]Sumitani M, Shibata M, Iwakura T, Matsuda Y, Sakaue G, Inoue T, Mashimo T, Miyauchi S. 660 Pathologic pain distorts visuospatial perception. Neurology 2007; 68: 152-4.

661 [98]Sutton S, Braren M, Zubin J, John ER. Evoked-potential correlates of stimulus uncertainly. Science 662 1965; 15: 1187-88.

663

[99]Taylor-Clarke M, Kennett S, Haggard P. Vision modulates somatosensory cortical processing. Curr 664 Biol 2002; 12: 233-6.

665

[100] Torta DM, Cauda F, Different functions in the cingulate cortex, a meta-analytic connectivity 666 modeling study. Neurolmage 2011; 56: 2157-72.

667

[101] Torta DM, Liang M, Valentini E, Mouraux A, lannetti GD. Dishabituation of laser-evoked EEG 668 responses: dissecting the effect of certain and uncertain changes in stimulus spatial location. Exp Brain Res 2012; 218: 361-72.

670

[102] Towell AD, Boyd SG. Sensory and cognitive components of the CO2 laser evoked cerebral potential. Electroencephalogr clin Neurophysiol 1993; 88: 237-9.

[103] Treede RD, Lorenz J, Baumgärtner U. Clinical usefulness of laser-evoked potentials. Neurophysiol Clin2003; 33: 303-14.

674 [104] Valentini E, Hu L, Chakrabarti B, Hu Y, Aglioti SM, lannetti GD. The primary somatosensory 675 cortex largely contributes to the early part of the cortical response elicited by nociceptive stimuli. Neurolmage 2012; 59: 1571-81.

677

[105] Valentini E, Torta DM, Mouraux A, lannetti GD.Dishabituation of laser-evoked EEG responses: 678 dissecting the effect of certain and uncertain changes in stimulus modality. J Cogn Neurosci, 679 2011; 23: 2822-37. 
680 [106] Valeriani M, Restuccia D, Le Pera D, De Armas L, Maiese T, Tonali P. Attention-related 681 modifications of ultra-late $\mathrm{CO} 2$ laser evoked potentials to human trigeminal nerve stimulation. $682 \quad$ Neurosci Lett 2002; 329: 329-33.

683 [107] Van Damme S, Legrain V, Vogt, J, Crombez G. Keeping pain in mind: a motivational 684 perspective on attentional processing of pain. Neurosci Biobehav Rev 2010; 34: 204-13.

685 [108] Van Ryckeghem DML, Van Damme S, Crombez G, Eccleston C, Verhoeven K, Legrain V. The 686 role of spatial attention in attentional control over pain: an experimental investigation. Exp Brain Res 2011; 208: 269-275.

688

[109] Walter WG, Cooper R, Aldridge VJ, McCallum WC, Winter AL. Contingent negative variation: an electric sign of sensori-motor association and expectancy in the human brain. Nature 1964; 203: 380-384.

691

[110] Wang X, Inui K, Qiu Y, Kakigi R. Cortical responses to noxious stimuli during sleep. Neuroscience 2004; 128: 177-86.

[111] Yamasaki H, Kakigi R, Watanabe S, Hoshiyama M. Effects of distraction on pain-related 694 somatosensory evoked magnetic fields and potentials following painful electrical stimulation. Cogn Brain Res 2000; 9: 165-75.

[112] Yamasaki H, Kakigi R, Watanabe S, Naka D. Effects of distraction on pain perception: magneto- and electro-encephalographic studies. Cogn Brain Res 1999; 8: 73-6.

[113] Zaslansky R, Sprecher E, Tenke CE, Hemli JA, Yarnitsky D. The P300 in pain evoked potentials. PAIN 1996; 66: 39-9.

700

[114] Zhang ZG, Lu H, Hung YS, Mouraux A, lannetti GD. Gamma-band oscillations in the primary somatosensory cortex - a direct and obligatory correlate of subjective pain intensity. J Neurosci, in press. 
Attention to stimulated hand

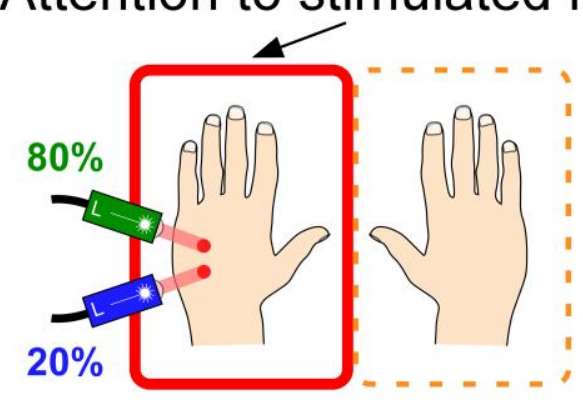

inside attentional focus
Attention to opposite hand

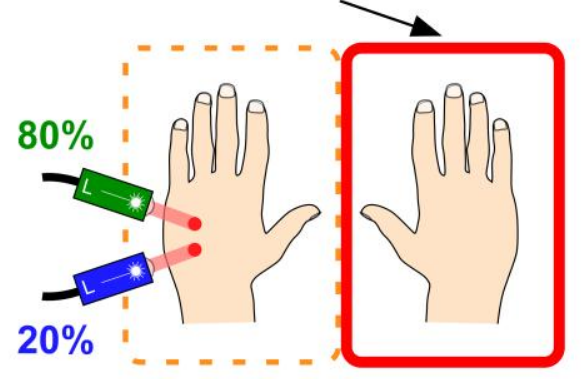

outside attentional focus:

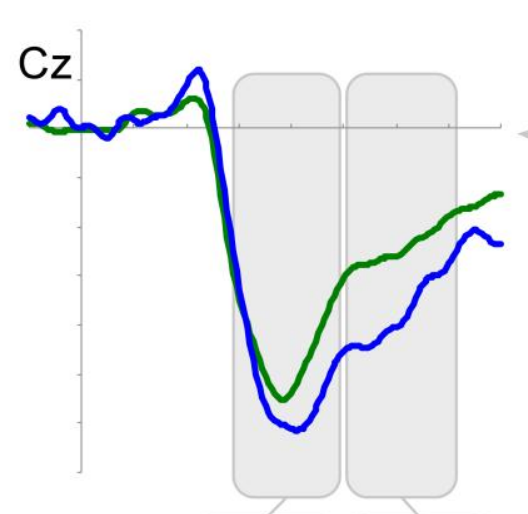

P2

P3

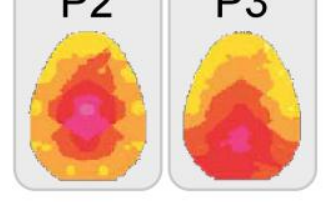

$-80 \%$

$-20 \%$

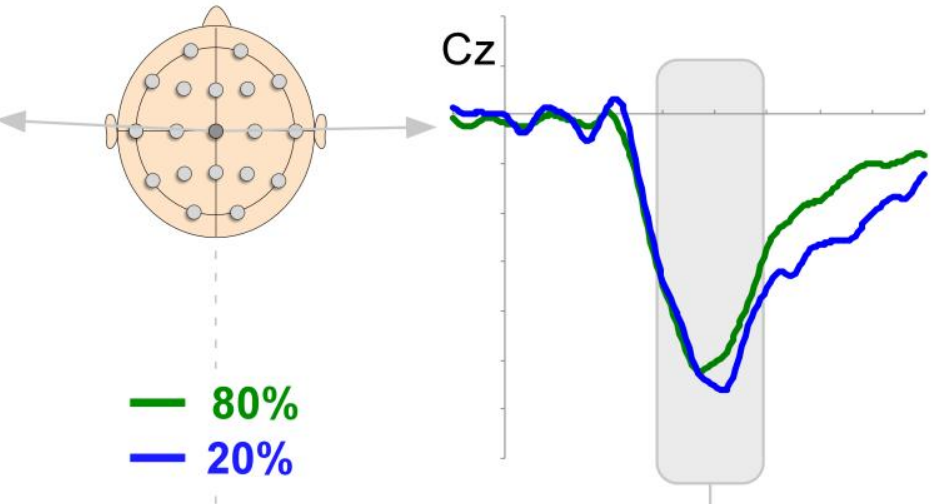

P2

Fig. 1. Bottom-up attentional effects on the nociceptive ERPs. Graphs illustrate ERPs recorded in different sessions in response to laser stimulus of the same intensity, but with different probabilities of occurrence. Laser stimuli were delivered either in regular and standard series of stimulation (green, $80 \%$ of trials), or in series of mismatching novel stimulation (i.e. their intensity was different than the standard stimuli delivered in the same block, blue, $20 \%$ of trials). The stimulated hand was either attended (left panel, red solid box), or unattended (right panel, orange dashed box). In the former case the novel stimuli were the targets of the task, in the latter case the novel stimuli were 
714 non-target stimuli with the same physical properties and the same probability of occurrence than the

715 targets. Amplitude of the P2 component, elicited at the vertex (see topographical maps, all

716 conditions merged), was larger in response to novel stimuli than is response to standard stimuli, both

717 on the attended hand and the unattended hand. The difference due to stimulus novelty was

718 nevertheless larger on the attended hand than on the unattended hand. Also note that the presence

719 of a parietal P3 component (or P300/P3b) was significantly observed only in response to the novel

720 stimuli on the attended hand (i.e. the targets) (the map in this time-window illustrates only the

721 topography of the ERPs elicited by the rare targets). This suggests that the participants only

722 responded to the rare targets, and not to rare non-targets. As a consequence the magnitude increase

723 for the P2 was indeed related to novelty-detection processes and partially independent from the

724 voluntary decision to detect the targets (adapted from [54]). 
Right hand stimulation

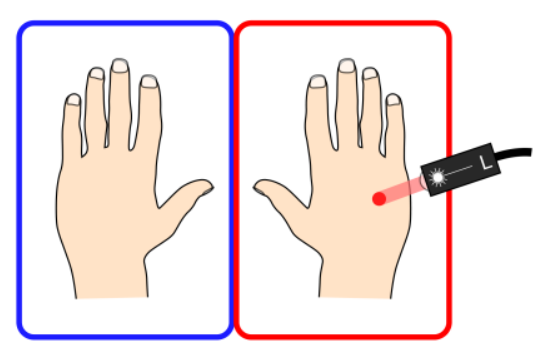

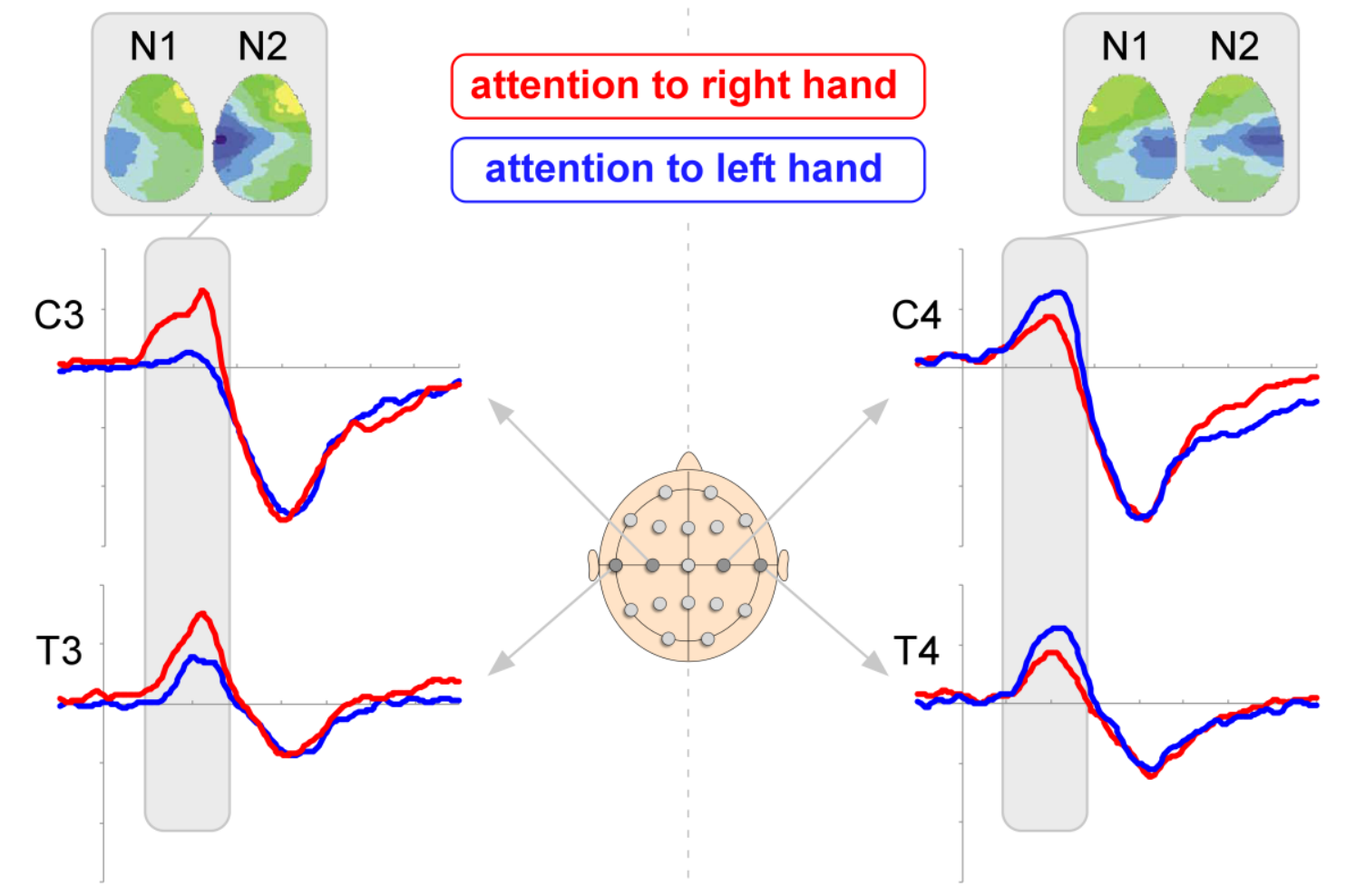

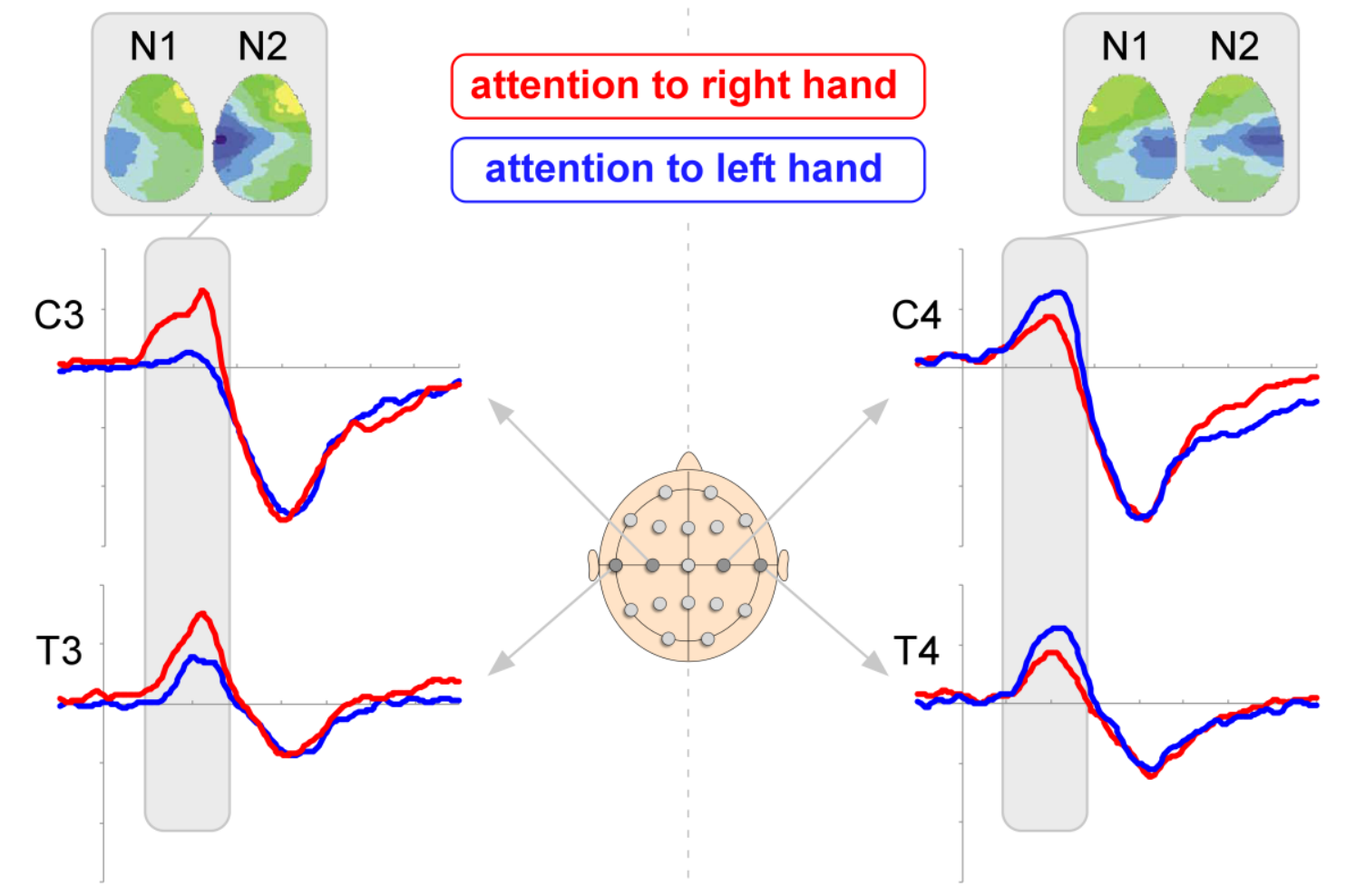

\section{Left hand stimulation}

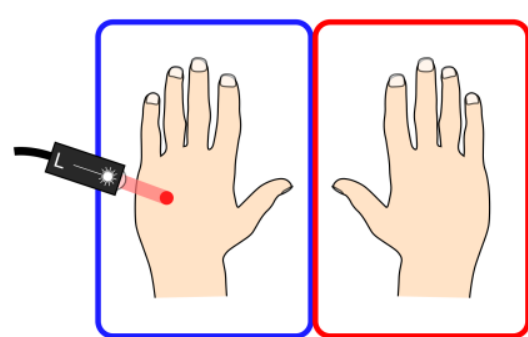

Fig. 2. Top-down attentional effects on the nociceptive ERPs. Laser stimuli were delivered randomly on the dorsum of the two hands. Participants were instructed to attend to the stimuli delivered of one hand and to detect occasional changes of stimulus intensity (i.e. targets), while ignoring all the stimuli delivered on the other hand. Graphs illustrate the ERPs elicited by attended and unattended non-targets stimuli. The left panel represents the ERPs recorded over the left hemisphere in response to right hand stimulation, the right panel the ERPs recorded over the right hemisphere in response to left hand stimulation. Topographical maps illustrate ERPs in the time-window of the N1 and N2 components (all "attention" conditions merged). Nociceptive stimuli of the right hand elicited ERPs of 
735

736

737

740

741

742

larger amplitude when the right hand was attended (red) than when the left hand was attended (blue). Similarly, left hand stimuli elicited ERPs of larger amplitude when the left hand was attended (blue) than when the right was attended (red). This modulation was observed as early as during the latency of the first laser-evoked component, i.e. N1 (adapted from [54]).

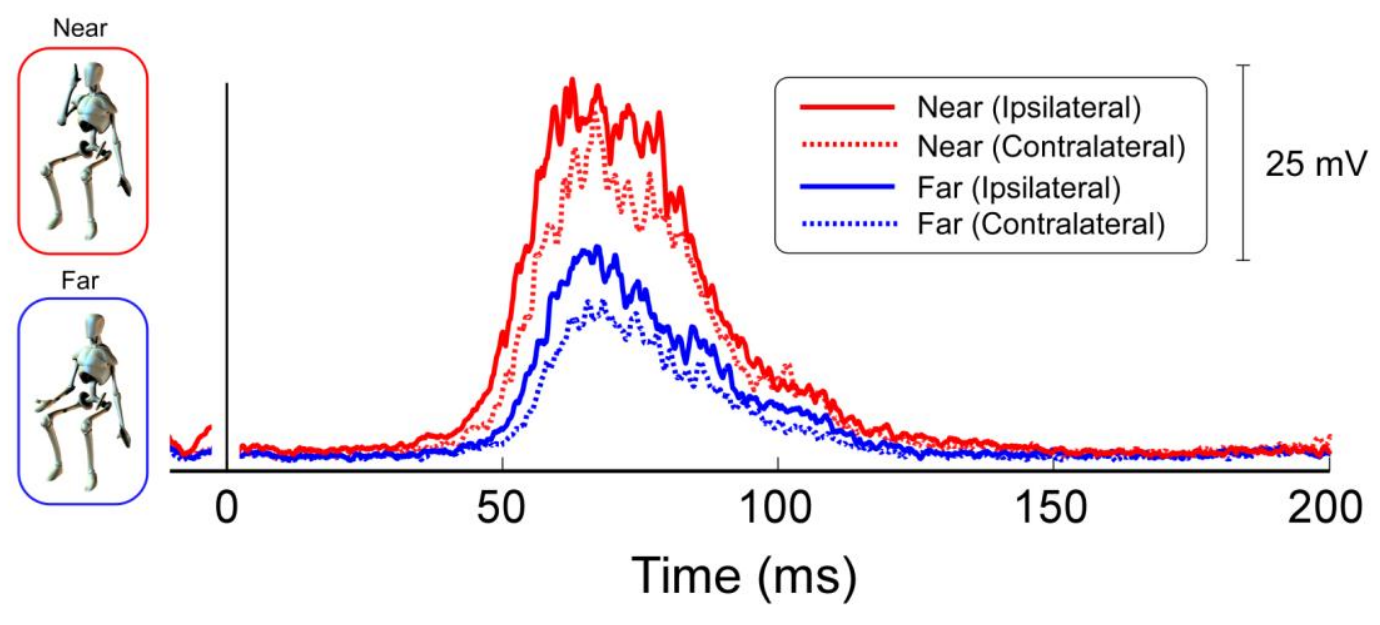

Fig. 3. Modulation of hand blink reflex by hand position. Blink reflex was elicited by intense electrical stimulation of the median nerve at the wrist, and electromyographic activity was recorded from the orbicularis oculi muscle (hand blink reflex or HBR).HBR was induced when the stimulated hand was near to the face (red lines) vs. far from the face (blue lines). The hand was positioned ipsilaterally (solid lines) vs. contralaterally (dashed lines) to the recording sites. The HBR had a significantly greater magnitude when the stimulated hand was near to the face than when it was far, and when the stimulated hand was ipsilateral than contralateral to the eye over which the HBR was recorded. This shows that brainstem activities mediating defensive reflexes can receive top-down modulation in order to respond adequately to external potential threats with respects to the position of the body parts (adapted from [90]). 